\title{
Detection of single and multiple pregnancy depending on placentomes measurement in Shami goats in Iraq by Ultrasonography Khawla A. Hussein
}

Department of Surgery and Obstetrics, College of Veterinary Medicine, Baghdad University, Iraq. E-mail: khawlaabbashussein@gmail.com

Received: 13/7/2017

Accepted: 26/8/2017

\section{Summary}

The aims of present study were designed to determine the relationship between fetal number single or twin and placentome measurement by real time Ultrasonography at different stage of pregnancy. Twenty mature female of shami goats were synchronized for estrus with vaginal sponges impregnated with $60 \mathrm{mg}$ of medroxey progesterone acetate (MAP) (Esponja-vet - spanin) under strict hygienic conditions, the sponges were inserted by applicator for 14 days, following by eCG (Folligon) intra muscularly injection each female goats (doe) received 500 IU Folligon. At the time of sponges withdrawl, estrus detection was done and each doe expressed estrus sings serviced naturally by buck proven fertility to obtain pregnancy. Result showed $100 \%$ of female express estrus after synchronized Ultrasound examination was performed by trans-rectally with linear probe $(7.5$ and $5 \mathrm{MHz})$ in early stage of pregnancy and using sector probe $(3.5 \mathrm{MHz})$ to trans-abdominal examination, the examination of animal started done from day 30 to 100 post mating every 5 day. The placentome was observed at first time of pregnancy at day 30 by using trans rectal examination with liner probe as an echo-genic parts on the surface of endometerium. The study showed a significant effect $(\mathrm{P} \leq 0.05)$ in placentome growth and gestation age. The placentome diameter reached maximum size at days 91-100 and was 34.76 $\pm 0.41 \mathrm{~mm}$. Also the present study showed no significant differences between placentome diameter in single and twin pregnant doe at $(\mathrm{P} \leq 0.05)$. The average of placentome size in single and twin was respectively, $7.72 \pm 0.46 \mathrm{~mm}$ and $8.42 \pm 0.34$ $\mathrm{mm}$ at day 30-41 of gestation, the measurements reached high value $(34.76 \pm 0.41 \mathrm{~mm})$ at day 91 100 of pregnancy. In conclusion the detection of gestation age in Shami goats according to placentome measurement was not a reliable method after day 90-100 of gestation. Also the placentome diameter measurement is not a practical method for diagnosing fetal number (single, twin) in pregnant Shami does.

Keywords: Ultrasonography, Pregnancy, Placentome, Shami goats.

\section{Introduction}

Shami goats are important animals, having a high ability to produce single, twin and triple pregnancy (1). In most flocks of animal natural breeding dates are not recorded and make it impossible to determine accurate information on gestation period to monitor time of birth (2). Synchronized estrus in live stock is one of the important methods in assisted reproductive technologies in goat reproduction (3). Placentome are composed of fetal cotyledon and maternal caruncle which are responsible for maternal fetal nutrient exchange in ruminants (1). They are easily to detect by trans- abdominal ultrasonography on day 35 of gestation and appear as echogenic areas on the surface of endometrial, and on day 40 placentome is imaged as cup-shape hyper echogenic area. Pregnant does with twins require more energy in late stage of pregnancy than in doe bearing singleton (4). Placentome diameter indicated the development of the placenta during pregnancy and the relationship between fetal and placental growth (5). Placentome diameter increased more in twin pregnancies than in singletons during the third month of pregnancy. (6) Considering that the placentome play an important role in maternal fetal nutrient exchange, it was hypothesized that placentome diameters may be different in goat bearing twin and single. Calculations of the number of fetuses would allow suitable nutritional management of the doe in late gestation that will prevent pregnancy toxemia (7) and reduce the incidence of dystocia (8). The objective of this study is to investigate the relationship between fetal number and estimation of placentome biometry during single and twin pregnancy of shami goat by Ultrasonography. 


\section{Materials and Methods}

Twenty (20) of female Shami goats were used in this study. They were selected randomly, their average age was (2-5 years). The study was carried out in a state board-for Agricultural Researches Station, Ministry of Agriculture of Baghdad (Agurgof). The animals were housed in semi opened shads provided with concentrated diet in two daily occasion supplemented with straw and green food presented to animal along with water. The animals were subjected to careful general and special clinical examination; the study extended six months. Estrus was synchronized with vaginal sponges impregnated with $60 \mathrm{mg}$ of medroxey acetate progesterone (MAP) (Esponja-vet - spanin) under strict hygienic conditions, the sponges were inserted by applicator (chrono-gest) for 14 days, following by 500 IU eCG (Folligon, intervet international B.V., Boxmeer The Netherland) for each goat at the time of sponges withdrawl. Estrus detection was done and each does expressed estrus sings serviced by buck proven fertility (8), according to naturally mated twice first and second day of estrus. All does were subjected to ultrasonographical examination starting from day 30-100 after mating and considered days of mating (9). Ultrasound examinations (trans-rectal and transabdominal) were done with different kinds of ultrasound. Brightness mode areal time Linear arrays, B- mod scanner equipped with two probes a $5 \mathrm{MHz}$ and $7.5 \mathrm{MHz}$ linear array prostate probe. (ALOKA Co Ltd USA). The second ultrasound machines convex/Liner ultrasound (HONDIA HS-2000/ 200V Japan) was equipped with probe $(3.5 \mathrm{MHz})$, and used light wave record connected with laptop. The probe before examination covered with ultrasound transmission gel. (10), in this study measured placentome diameter in millimeters by Ultrasonography, in single and twin pregnancy, and selected big size placentomes.

Statistical analysis: All measurements were in millimeter $(\mathrm{mm})$. Means were compared by using T-test. Significant between different observations (Table, 1) and used least significant differences -LSD test was used significant between different observations of each measurement of (Table, 2) in this study.
Results and Discussion

The results in (Table, 1) showed a rapid increase of placentome diameter from days 3040 to 90-100. Different small letters mean significant differences $(\mathrm{P} \leq 0.05)$. The observed disagreement with other previous study (11), might be related to the difference of animal species. The results showed the earliest detection of placentomes and some parts of fetus by using method of transrectal real time ultrasonography $(7.5 \mathrm{MHz})$ was possible at day 30 of pregnancy in shami goats (Table, 1), the results with (7) who recorded that examination was not possible in day 30 of gestation which could be due to the variation in probe and operator and difficulty in imaging the distance of uterus. The results indicated a relationship between placentom diameter and gestation period. The mean values of placentome diameter in (Table, 1) showed significant differences $(\mathrm{P} \leq 0.05), \quad$ and placentome diameter reached a maximum size at days (81-90 and 91-100), (34.46 \pm 0.55 and $34.76 \pm 0.41)$ respectively, and the least value at day 30-40 of pregnancy. Several studies have detected the placentomes size by transrectal and trans- abdominal ultrasonography at days 25 to 40 of pregnancy as a small nodule to white circular structure (12). The placentomes were measured up to day 100 of pregnancy. These results were in disagreement with (13) who recorded that it was possible to observe and measure up to day 135 of pregnancy. Differences in the detection of placentomes may be ascribed to the type of equipment, the model of sonar and probe (14) used and age of animal. The results of (Table, 1) showed a significant effect $(\mathrm{P} \leq 0.05)$ in placentomes diameter between single and multiple pregnancies. These agreed with results of (15).

Table, 1: Ultrasonography measurements of placentome at different period of pregnancy in shami goats.

\begin{tabular}{|cc|}
\hline Gestation age (day) & Placentome diameter $(\mathbf{m m})$ \\
\hline $30-40$ & $\mathbf{8 . 0 7} \pm \mathbf{0 . 6 2}$ f \\
$41-50$ & $\mathbf{1 2 . 2 3} \pm \mathbf{0 . 4 9} \mathbf{e}$ \\
$51-60$ & $\mathbf{1 7 . 4 3} \pm \mathbf{0 . 4 5} \mathbf{d}$ \\
$61-70$ & $\mathbf{2 5 . 6 7} \pm \mathbf{0 . 5 1}$ c \\
$71-80$ & $\mathbf{2 8 . 9 7} \pm \mathbf{0 . 7 2}$ b \\
$81-90$ & $\mathbf{3 4 . 4 6} \pm \mathbf{0 . 5 5} \mathbf{a}$ \\
$91-100$ & $\mathbf{3 4 . 7 6} \pm \mathbf{0 . 4 1} \mathbf{~ a}$ \\
\hline LSD & 3.72 \\
\hline
\end{tabular}


Means were compared by using unpaired ttest; all differences were not significant $(\mathrm{P} \leq 0.05)$, (Table, 2) showed a rapid increase of placentome diameter from days 30-40 to 90100 in single and twin pregnancy. There was observed a disagreement with other previous study, the differences might be related to the difference of animal species. There is no doubt that accuracy of the method in recognized placentome is very high if the operator is sufficiently skilled (16). The average of placentome size in single and twin pregnancy does was $7.72 \pm 0.46 \mathrm{~mm}$ and $8.42 \pm 0.34 \mathrm{~mm}$ respectively, at day 30-40 of pregnancy. Larger placentome are estimated in twins pregnancy (17). The maximal size of placentome was $34.62 \pm 0.57 \mathrm{~mm}$ in single pregnancy at days $91-100$ of gestation and $34.62 \pm 0.57$ during 91-100 of gestation. These results showed no significant differences increase $(\mathrm{P} \leq 0.05) \quad$ between placentome measurements in single and twin pregnancy in Shami goats. The results disagree with previous study (18) who showed that placentome measurement increase more in twin pregnancy than in single pregnancy during day 90 of gestation. The present study in agreement with (19) who reported no differences between single and twin measurement. This study investigated the estimation of pregnancy age in Shami goats according to placentome diameter measurement, which was not reliable after day 90-100. These results agreed with (20 and 21). Additionally in the current study, it was reported that these placentome measurements were not helpful in predicting gestation in single and twin pregnancies. This study investigated the estimation of pregnancy age in Shami goats according to placentome diameter. Measurement was not reliable after day 90-100. This result was agreed with $(1,13$ and 19). Additionally in current study, it was reported that these placentome measurements were not helpful in prediction of gestation in single and twin. The results of (Table, 1) showed that there was significant effect $(\mathrm{P} \leq 0.05)$ in placentomes diameter between single and multiple pregnancies. These observations agreed with result of (17). In conclusion the detection of gestation age in Shami goats according to placentome measurement was not a reliable method after day 90-100 of gestation. Also placentome diameter measurement is not a practical method for diagnosing fetal number (single, twin) in pregnant shami goats.

Table, 2: Placentome diameter measurements by Ultrasonography in single and twin during different stage of pregnancy in Shami goats by Ultrasonography.

\begin{tabular}{|c|c|c|c|}
\hline $\begin{array}{l}\text { pregnancy } \\
\text { period } \\
\text { (Days) }\end{array}$ & $\begin{array}{c}\text { Placentome } \\
\text { diameter } \\
(\mathrm{mm}) \text { in single } \\
\text { pregnancy }\end{array}$ & $\begin{array}{l}\text { Placentome } \\
\text { diameter } \\
(\mathrm{mm}) \text { in twin } \\
\text { pregnancy }\end{array}$ & $*(P \leq 0.05)$ \\
\hline $30-40$ & $7.72 \pm 0.46$ & $8.42 \pm 0.34$ & 0.24 \\
\hline $41-50$ & $12.20 \pm 0.51$ & $12.26 \pm 0.47$ & 0.31 \\
\hline $51-60$ & $17.11 \pm 0.63$ & $17.79 \pm 0.68$ & 0.47 \\
\hline $61-70$ & $25.28 \pm 0.71$ & $26.07 \pm 0.41$ & 0.34 \\
\hline $71-80$ & $28.33 \pm 0.83$ & $29.61 \pm 0.95$ & 0.32 \\
\hline $81-90$ & $34.42 \pm 0.61$ & $34.50 \pm 0.46$ & 0.61 \\
\hline $91-100$ & $34.62 \pm 0.57$ & $34.62 \pm 0.57$ & 0.68 \\
\hline
\end{tabular}

The result in (Fig. 1) shows an image of placentom at day 35 in single and twin of pregnancy Shami goats, the placentom appear like white circles and echogenic by Ultrasonography.

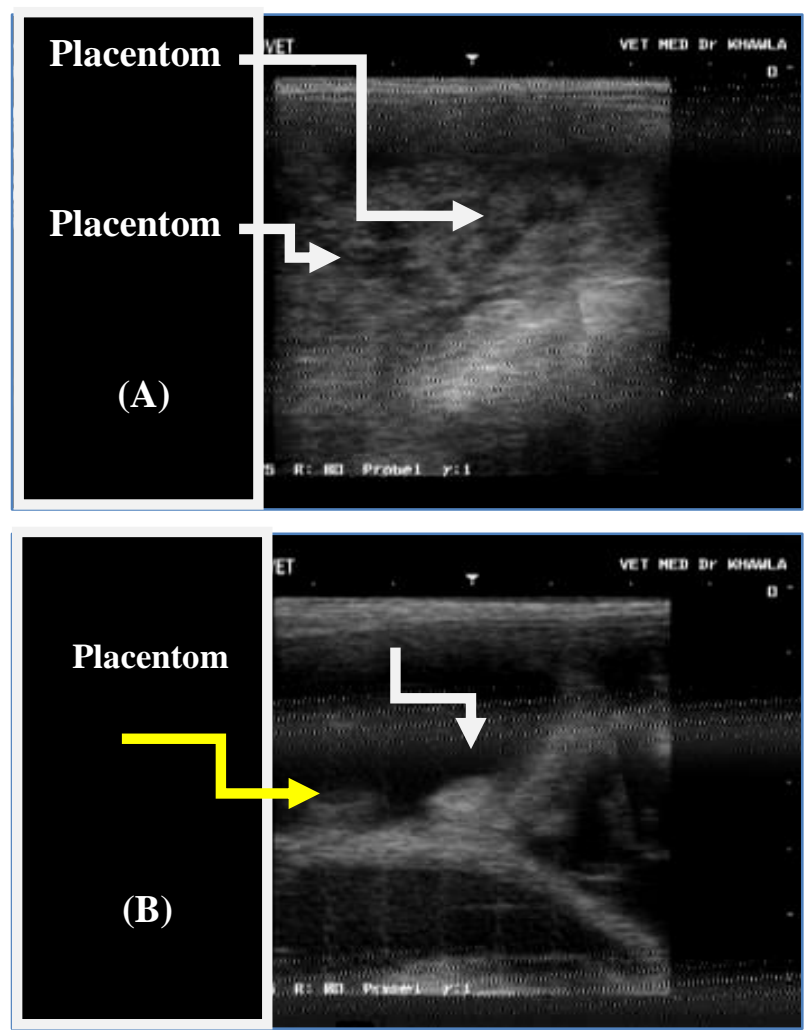

Figure, 1: Placentom size (mm) at day 35 of pregnancy in Shami goats in Iraq early stage. (A) in single pregnancy (B) in twin pregnancy.

The result in (Fig. 2) shows an image of placentom at day 40 in single and twin of pregnancy examind by trans-rectally with probe $7.5 \mathrm{MHz}$ (A: single, B: twin pregnancy). 

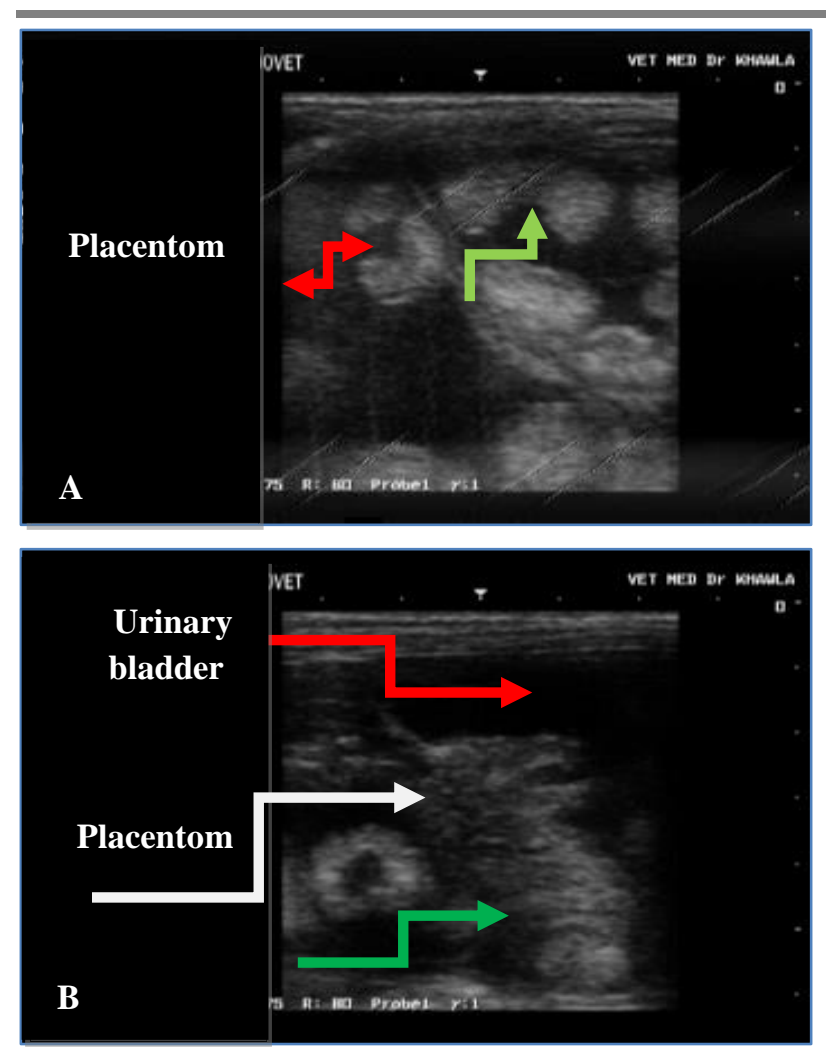

Figure, 2: Placentom size at days 40 of pregnancy in Shami goats. (early stage).

The result in (Fig. 3) shows an image of placentom at day 50 in single and twin of pregnancy examined trans-abdominally with probe $3.5 \mathrm{MHz}$ (A :single, B: twin pregnancy).

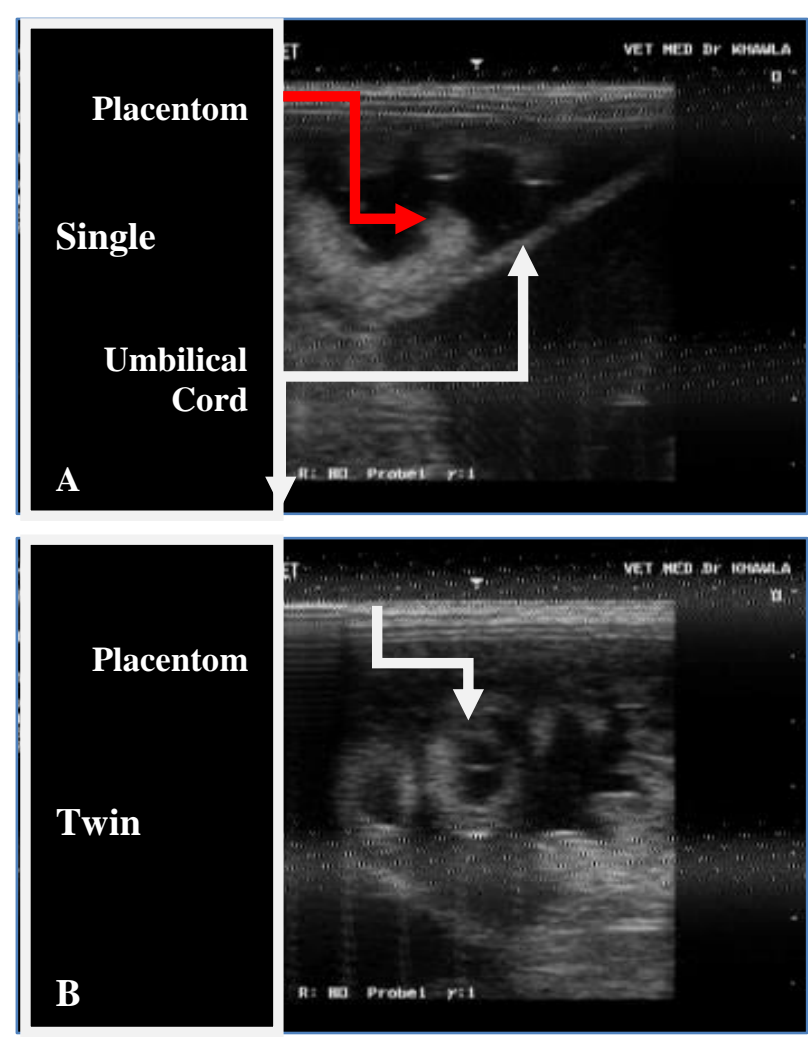

Figure, 3: Placentom size at days 50 of pregnancy in Shami goats . (Advance stage).
The result in (Fig. 4) shows an image of placentom at day 75 in single and twin of pregnancy examined trans-abdominally with probe $3.5 \mathrm{MHz}$ (A: single, B: twin pregnancy.
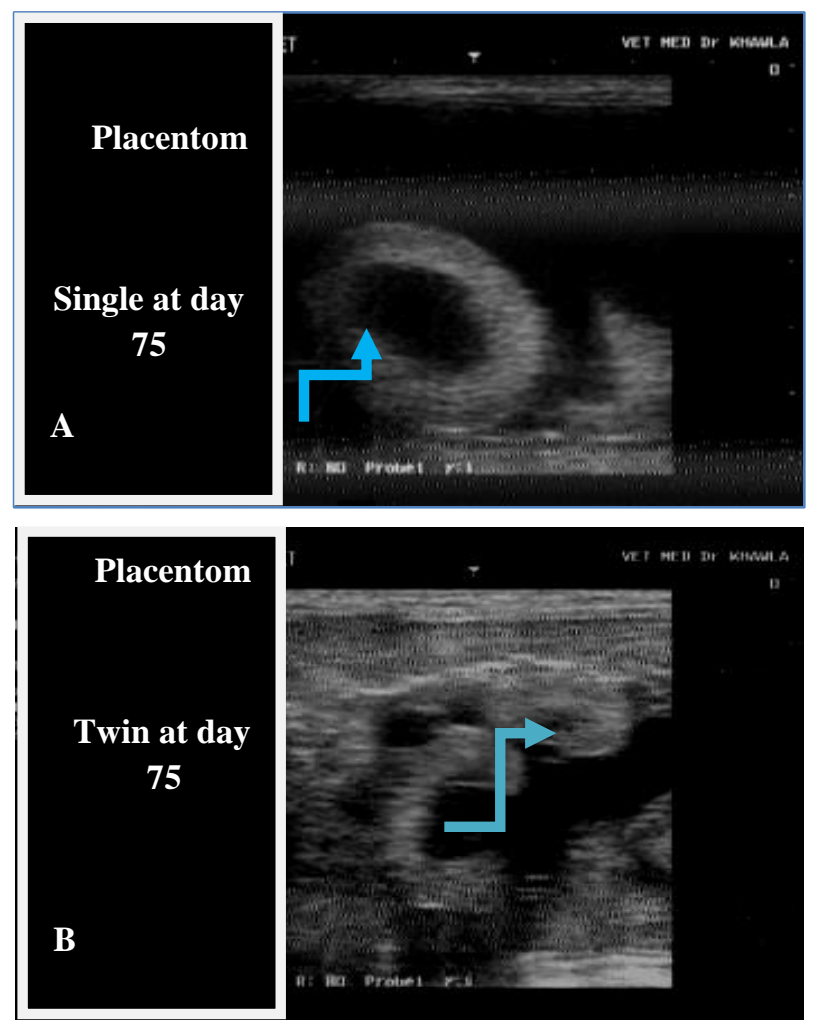

Figure, 4: Placentom size at days 75 of pregnancy in Shami goats . (Advance stage).

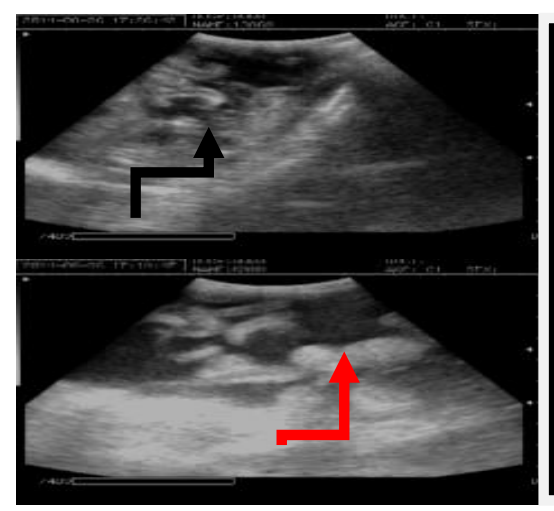

Placentom

At day 80 of

pregnancy

in single and

twin

A

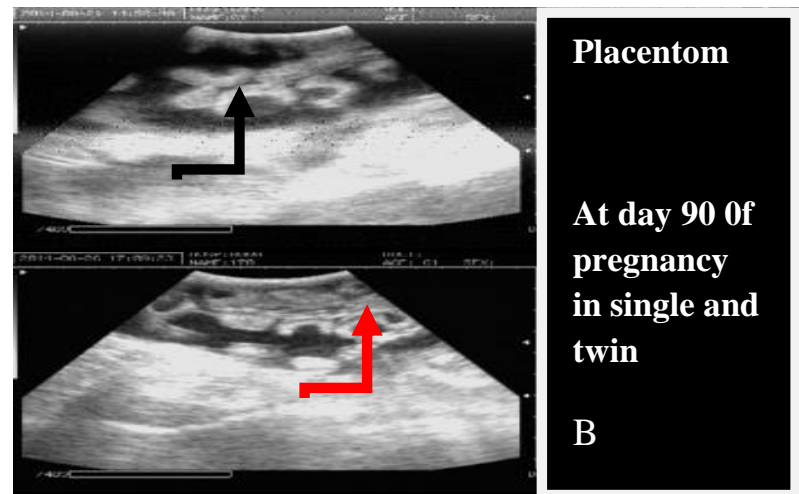

Figure, 5: Real time-B-mode Ultrasonography image of placentome of pregnant doe using transabdominal examination during 80 and 90 day of pregnancy in shami goats. 


\section{Acknowledgements}

My deepest thanks and appreciations are paid to Prof. Dr. Hani. M. Al Rawi, the Dean of Scientific Affairs, College of Veterinary Medicine, University of Allfaloja. Deep gratitude should go to all members of agriculture research center, for their help.

\section{References}

1. Rawlings, N.C.; Jeff Coate, I.A.; Savage, N. C.; Steuart, D.M.K. and Steuart, L.H.M. (1983). Pregnancy diagnosis and assessment of fetal numbers in the ewe in a commercial setting. Theriogenol., 19:655-663.

2. Doizé, F.; Vaillancourt, D.; Carabin, H. and Bélanger, D. (1997). Determination of gestational age in sheep and goats using ransrectal ultrasonographic measurement of placentomes. Theriogenl. Eriogenol., 48: 449-460.

3. Kelly, R.W. and Newnham, J.P. (1989). Estimation of gestational age in Merino ewe by ultrasound measurement of fetal head size. Aust. J. Agri. Res., 40:1293-1299.

4. West, D.M. (1986). Pregnancy diagnose in the ewe. In: Morrow, D.A., Ed. Current Therapy in Theriogenology. $2^{\text {nd }}$ ed, W.B. Saunders Co., Philadelphia. Pp:850-852.

5. Kaulfuss, K.H.; Uhlich, K. and Gille, U. (1998). Ultrasonographic examination of the placentome development in pregnant sheep. Dtsch. Tierarztl Wochenscrh; 105: 162-167.

6. Yotov, S. (2005). Diagnostics of early pregnancy in Stara Zagora dairy sheep breed. Bulgarian J. Vet. Med., 8:41-45.

7. Aydın, İ.; Elik, H.A.; Şendağ, S. and Dinç, D.A. (2008). Determination of placentome development and gestational age by ultrasonographic measurements in ewes. Vet. Bil. Derg., 24:29-34.

8. Alexander, G. (1964). Studies on the placenta of the sheep (Ovis aries): placental size. J. Reprod. Fert., 7:289-305.

9. Vonnahme, K.A.; Arndt, W.J.; Johnson, M.L.; Borowicz, P.P. and Reynolds, L.P. (2000). Effect of morphology on placentome size, vascularity and vasoreactivity in late pregnant sheep. Biol.
10. SAS. (2012). Staticall analysis system, users guide statically version $9.1^{\text {th }}$ ed. SAS. Inst, Inc carry. NC . USA.

11. Abdelghafar, R.M. (2006). B Mod real time ultrasonography for pregnancy diagnosis and fetometry in sannen goat M. Sc Thesis Sudan Univ. Tech., Pp:71. Kari sheep. lap lambert

12. Ali, A. and Hayder, M. (2007). Ultrasonographic assessment of embryonic, fetal and placental development in Ossimi sheep. Small Ruminant Res., 73:277-282.

13. AL-Rawi, H.M. (2005). Clinical uses of ultrasonic technique in reproductive management in ewes. Ph.D. thesis. College of Veterinary.

14. Boyd, J.S. and Omran, S.N. (1991). Diagnostic ultrasonography of the bovine female reproductive tract. In Practice. 13(3):109-116, 118.

15. Das, G.K.; Khan, G.A. and Pande, M. (2011). Pregnancy diagnosis in small ruminants: An overview. Indian J. Small Ruminants, 17:21-31.

16. Davey, C.G. (1986). An evaluation of pregnancy testing in sheep using a real-time ultrasound scanner. Australian Vet. J., 63: 347- 348.

17. Dawson, L.J. (1999). Pregnancy diagnosis in goats. In: Proceedings of the 14th Annual Goat Field Day, Langston University,

18. Engeland, I.V.; Ropstad, E.; Kindal, H.; Andersen, O.; Waldeland, H. and Tevedal, A. (1999). Foteal loss in dairy goatsfunction of the adrenal glands, corpus lutem and the foteal-placental unit. Anim. Reprod. Sci., 55:205-222.

19. Kelly, R.; Newnham, J.; Johnson, T. and Speijers, E. (1987). An ultrasound technique to measure placental growth in ewe. Aus. J. Agric. Res., 38:575-764.

20. Schrick, F.M.; Inskeep, E.K. (1993). Determination of early pregnancy in ewes utilizing transrectal ultrasonography. Theriogenol., 40:295-306.

21. Zarkawi, M.; Al-Merestani, M.R. and Wardeh, M.F. (1999). Induction of synchronised oestrous in indigenous Damascus goats outside the breeding season. Small Rumin. Res., 33:193-197. 

الكثف عن الحمل المفرد والتوأمي اعثماداً على قياس القلقات للماعز الشامي في العراق بالموجات فوق الصوثية

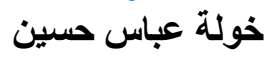

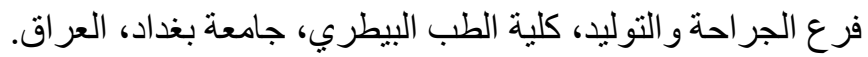

E-mail: khawlaabbashussein@gmail.com

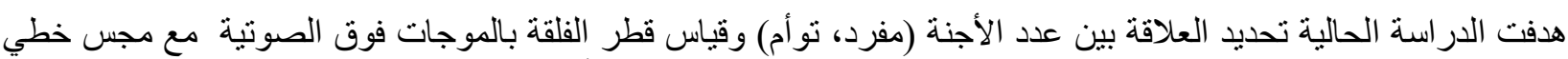

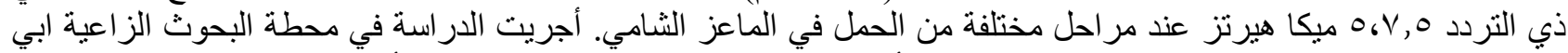

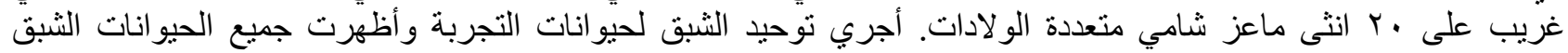

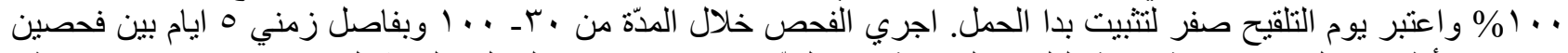

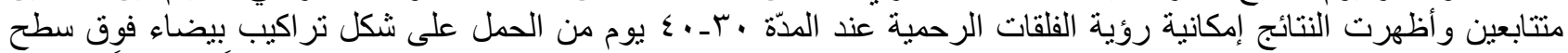

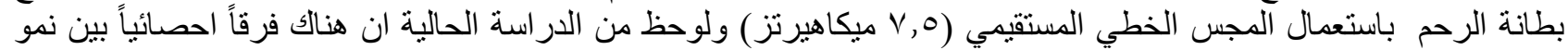

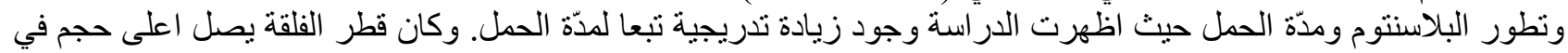

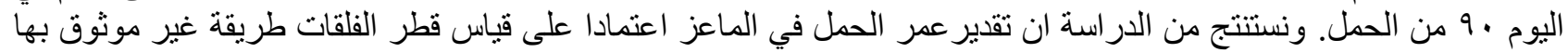

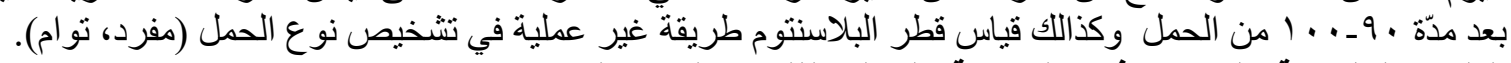

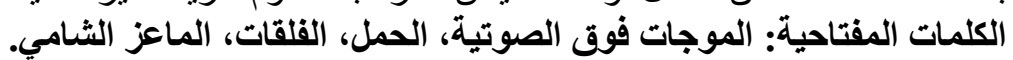

